\title{
COMPARAÇÃO DA COBERTURA VACINAL BRASILEIRA DO ANO DE 2015 AO ANO DE 2020: A QUEDA DA IMUNIZAÇÃO NO BRASIL
}

\section{COMPARISON OF BRAZILIAN VACCINATION COVERAGE FROM 2015 TO 2020: THE FALL OF IMMUNIZATION IN BRAZIL}

Maria Eduarda Baroni Sardi ${ }^{1^{*}}$, Leonardo Proença Silva ${ }^{1}$, Maria Thereza Bordignon Tozzo ${ }^{1}$, Mariana Dos Santos Simião', Mariana Gularte ${ }^{1}$, Marina Candido Da Silva ${ }^{1}$, Luiz Renato Manfredini Hapner ${ }^{2}$.

1 UNINGÁ - Centro Universitário Ingá, Maringá, PR, Brasil.

${ }^{2}$ Universidade Federal do Paraná, Curitiba, PR, Brasil.

*mariaeduardabaronisardi@gmail.com

\section{RESUMO}

O Programa Nacional de Imunizações, formulado pelo Ministério da Saúde, tem como maior objetivo instituir o calendário vacinal e distribuir vacinas, de forma gratuita, em âmbito nacional. Dessa forma, a imunização é uma das intervenções mais bem-sucedidas no controle de diversas doenças, entretanto, uma importante queda na cobertura vacinal tem sido observada no Brasil, aumentando o risco de doenças consideradas erradicadas. Dessa maneira, o objetivo é comparar a cobertura vacinal brasileira do ano de 2015 ao ano de 2020 e demonstrar a importância da vacinação e a provável segunda queda consecutiva da cobertura vacinal para o ano de 2020. As fontes de dados utilizadas foram retiradas do Departamento de Informática do Sistema Único de Saúde (DATASUS) e a população em estudo corresponde a homens e mulheres, sem restrição de faixas etárias, residentes no Brasil. Desse modo, em 2015, a média da cobertura vacinal das cinco regiões brasileiras (norte, nordeste, sudeste, sul e centro-oeste), foi de 95,07\%. No ano seguinte, em 2016, a cobertura vacinal teve uma queda brusca para $50,44 \%$, e em 2017 a taxa foi de $72,93 \%$. Já no ano de 2018, a média ascendeu para $77,13 \%$, porém, em 2019 , caiu novamente para $72,74 \%$. Considerando o atual mês do ano de 2020 (setembro), a taxa de vacinação de janeiro a setembro foi de $51,62 \%$. Em relação à média de todos os anos, a região norte foi a que apresentou menor cobertura vacinal comparada com as outras regiões brasileiras. Nessa perspectiva, ao analisarmos a cobertura vacinal dos últimos anos, vemos como é drástica a queda da cobertura vacinal em uma comparação do ano de 2015 aos anos subsequentes. Além do mais, observamos uma notável queda no ano de 2019, e provável nova queda consecutiva para o ano de 2020, já que a cobertura vacinal de janeiro a setembro atingiu apenas $51,62 \%$. Isso se deve em parte a atual epidemia do novo Coronavírus, em que grande parte da população evita ir às Unidades de Saúde buscar pelas vacinas; além disso, recentemente, vivenciamos o "Movimento antivacina" que, apesar das inúmeras demonstrações da eficácia e importância das vacinas, cresce o número de pessoas que recusam a vacinar seus filhos, fomentando um movimento perigoso que pode trazer de volta doenças como a poliomielite. Entretanto, vale ressaltar que estes são apenas dois dos motivos os quais a queda foi atribuída, necessitando de mais pesquisas para elucidar o porquê a população brasileira está deixando de 
procurar as imunizações. Dessa maneira, apesar de no Brasil a vacinação ser gratuita, com a queda na imunização, há risco de aumento de casos de doenças que já foram consideradas erradicadas.

Palavras-chave: Cobertura vacinal. Erradicação de doenças. Imunização. Movimento antivacina. Programas de imunização. 